\title{
Pro-oxidant and pro-inflammatory Micro-RNAS profile as a risk factor for postoperative atrial fibrillation
}

\author{
Rodrigo L Castillo ${ }^{1,2 *}$, Daniela F Henríquez ${ }^{3}$, Aníbal E Méndez ${ }^{3}$, Jorge G Farías ${ }^{4}$ and Catalina Carrasco-Pozo $^{5}$ \\ ${ }^{1}$ Departamento de Medicina Interna Oriente, Facultad de Medicina, Universidad de Chile, Santiago, Chile \\ ${ }^{2}$ Unidad de Paciente Crítico, Hospital del Salvador, Santiago, Chile \\ ${ }^{3}$ Departamento de Fisiopatología, Programa de Ayudantes Alumnos, Facultad de Medicina Oriente Universidad de Chile, Santiago, Chile \\ ${ }^{4}$ Departmento de Ingeniería Química, Facultad de Ingeniería y Ciencias, Universidad de La Frontera, Francisco Salazar, Chile \\ ${ }^{5}$ Discovery Biology, Griffith Institute for Drug Discovery, Griffith University, Nathan, QLD 4111, Australia
}

\begin{abstract}
Atrial fibrillation (AF) is the most commonly encountered arrhythmia after cardiac surgery with extracorporeal circulation. Although usually self-limiting and represents an important predictor of increased patient morbidity, mortality and health care costs. Numerous studies have attempted to determine the underlying mechanisms of postoperative atrial fibrillation (POAF) with varied success. POAF comprises a multifactorial pathophysiology, in which inflammation and oxidative stress (OS) play a critical role. Studies have shown that microRNAs (miRNA), may be involved in the pathophysiology of AF determine a link between inflammation and OS occurrence. Also, in chronic patients, miRNAs have been implicated in AF-induced ion channel remodeling and fibrosis. However, the role of miRNA in POAF is not well defined. We will be tested the hypotheses that the development of POAF is associated with pro-inflammatory and pro-oxidant miRNA profile in blood, atrial and PF samples. These changes are attenuated by the administration of antagomiRs or microRNA mimics in ex vivo model of atrial fibrillation. In animal ex vivo model of AF, the effect of candidate miRNAs on the duration of arrhythmia and markers of oxidative stress, inflammation and mitochondrial dysfunction in cardiac tissue are presented. The contribution of miRNAs will be determined by blocking these candidate miRNAs with specific antagonists to establish effects on ex vivo AF duration and left ventricular function. The ex vivo model of AF could allow to define some molecular targets that would modulate these miRNAs, and contributes to cardiac arrhythmogenesis.
\end{abstract}

\section{Introduction}

The mechanisms underlying the development of complications associated with cardiac surgery are multifactorial and have been related to inflammation and oxidative stress, classically measured in the blood or plasma of patients. This is important since cardiac surgery alters the integrity of the pericardial membrane and causes significant alterations in the pericardial fluid (PF) composition. This can potentially have adverse effects on the thin-walled atria leading to postoperative atrial fibrillation (POAF). After cardiac surgery, the pericardium remains open, and chest drains are routinely placed to prevent fluid accumulation around the heart. It have been described that the concentration and trajectory of blood proinflammatory factors increased in the PF after cardiac surgery over time [1]. Kramer et al. demonstrated an increase in the neutrophil infiltration in PF after 4 and $48 \mathrm{~h}$ postcardiac surgery over PF levels at time 0 . Lipid peroxidation products of arachidonic acid-derived isoprostane 8-isoprostaglandin F2- $\alpha$ and its stereoisomer 8-iso-15-prostaglandin F2 $\alpha$ (F2 isoprostanes) were elevated in PF after 4 and $12 \mathrm{~h}$ following surgery and returned to PCF levels at time 0 after 24 to $48 \mathrm{~h}$. Such increase of the levels of these pathological stimulants coupled with underlying atrial myocardial pathology can amplify the direct myocardial insult of a cardiac operation and may potentially contribute to the risk for postoperative AF [2]. As an opposite mechanism, it is also suggested that the elimination of the FP by pericardial drainage would reduce the pro-inflammatory injury. However, there is clinical evidence that increases complications and POAF occurrence [3]. Therefore, current evidence of how the composition of PF influences POAF and its change during surgery is inconsistent and requires further study.

\section{Post-operative atrial fibrillation pathophysiology}

Postoperative AF (POAF) frequently occurs as a complication of cardiac surgery with extracorporeal circulation, associated with an increase hospital stay, medical costs and overall mortality [4]. This arrhythmia has a high incidence, between 27 and $40 \%$, despite the optimization in anesthetic protocols, surgical techniques, medical treatment and the wide use of antiarrhythmics such as beta-blockers and amiodarone [5]. Therefore, due to the suboptimal efficacy of perioperative pharmacological treatment, the search for new markers and pharmacological targets becomes necessary. Although the exact pathophysiology of POAF remains unclear, it is multifactorial in its origin. Patient related factors known to contribute include atrial dilatation: age-related fibrosis, cardiac structural damage, hypertension, and other comorbid conditions [6,7] The concept of

${ }^{\star}$ Correspondence to: Rodrigo L Castillo, Departamento Medicina Interna Oriente, Facultad de Medicina, Universidad de Chile, Unidad de Paciente Crítico, Hospital Salvador, Santiago, Chile, E-mail: rcastillo@med.uchile.cl; rodrigouch@gmail.com

Key words: extracorporeal circulation, ischemia-reperfusion, postoperative atrial fibrillation, microRNAs

Received: November 15, 2019; Accepted: November 22, 2019; Published: November 28, 2019 
(structural) predisposition for AF seems to be true for vulnerability of certain patients to AF after cardiac surgery. The electrophysiological substrate may be pre-existing or may develop because of heterogeneity of refractoriness after surgery [8]. Furthermore, the role of ectopic beats from the pulmonary veins in the development of POAF, as in nonsurgical patients, is yet to be delineated [9]. Several factors related to the surgical procedure also potentially contribute to the development of AF. These include operative trauma from surgical dissection and manipulation, pericardial lesions (pericarditis), atrial dilatation (caused by left ventricular dysfunction and intraoperative volume overload), perioperative use of catecholamines, parasympathetic activation, and electrolyte imbalances $[7,10,11]$. Current cardioplegia techniques and inadequate atrial cooling may be responsible for atrial ischemia. This has led some to postulate that ischemic injury and subsequent oxidative stress on reperfusion are potential triggers for POAF [12].

ROS generation is appreciated to occur during ischemia despite the low oxygen tension, from a likely mitochondria source, and ROS-induced ROS release may amplify its signal. The burst of ROS seen during reperfusion may originate from a different cellular source than during ischemia and is not yet fully identified $[13,14]$. This oxidative burst could cause and determine, in part, electrical remodeling processes that would trigger greater re-entry activity and, therefore, greater susceptibility to developing AF [15]. Regarding the inflammation, in atrial tissue from AF patients with valvular heart disease, there were significant positive correlations among NF- $\kappa B$ activity, serum TNF- $\alpha$ and IL- 6 levels, and collagen volume fraction [16]. Serum levels of the fibro-inflammatory biomarkers MMP-9, type III procollagen, and hs-CRP, were greater in persistent-AF patients than in SR controls, and positively correlated with echocardiographic left atrial volume, an index of atrial remodeling $[17,18]$. It is important to distinguish between the contribution of inflammatory cells that migrate due to the phenomenon of surgical injury $v s$. The generation of local inflammation in the atrial tissue [19].

\section{Participation of oxidative stress in the mechanisms inducing POAF}

The technical procedure applied in cardiac surgeries implies an injury against the myocardial tissue, fundamentally derived from the changes of perfusion, and therefore, oxygenation, giving rise in this way to the formation of reactive oxygen species (ROS). Several mechanisms such as mitochondrial respiration and neutrophils activation generate ROS $[14,20]$. The production of free radicals in the early phase of reperfusion, combined with the decrease in antioxidant defences induced by ischemia reperfusion (IR), makes the myocardial tissue extremely vulnerable to oxidative damage. Among these, the superoxide anion (O2-), the hydroxyl radical $(\mathrm{OH}-)$ and the peroxynitrite (NOO) are key species underlying the mechanism of damage in different experimental models, as well as in individuals subjected to postinfarction thrombolysis and stroke [21,22], to percutaneous angioplasty $[23,24]$ or to cardiothoracic surgery $[25,26]$. As the cell membranes are composed mainly of phospholipids and proteins, alterations in membrane proteins by these ROS are important factors in the evolution of atrial tissue damage by IR. In the case of lipids, lipoperoxidation and the loss of membrane integrity trigger drop ATP levels and cytosolic calcium overload, which lead to cell death [27]. In addition, ROS act in the form of mediators or messengers, triggering intracellular signals. Thus, transcriptional factors, such as NF- $\mathrm{BB}$, can be activated by ROS, which in turn activates the expression of pro-inflammatory genes $[28,29]$. Once the inflammatory process is initiated, transmigration and activation of the leukocytes takes place, which contributes to enhance local oxidative stress. The release of mediators such as cytokines, chemokines and adhesion molecules, all of which exacerbate the tissue damage, even areas of necrosis of the myocardial fiber can be generated $[30,31]$. The next step, the repair involves the risk of collagen deposition in the extracellular matrix, a process of interstitial fibrosis that would affect the functional properties, both electrical and mechanical, of the myocardium. Thus, in vitro studies, increase ROS concentration have shown affect the contractile function of cardiomyocytes associated with calcium overload and major sensitivity of myofilaments, as a arrhythmogenic mechanism [32,33].

\section{Mitochondrial function}

Recent experimental evidence suggests that changes of levels of phosphocreatine, electron transfer chain proteins and differences in mitochondrial distribution further imply that mitochondria play a role in AF [34]. Mitochondrial dysfunction leading to mitochondrial ROS production is implicated in ryanodine receptor oxidation facilitating $\mathrm{Ca}^{2+}$ leak and AF development [35,36]. Also, an interesting ex vivo study using atrial tissue from patients with and without AF showed that inward calcium L-type channels remodeling contributes to mitochondrial oxidative stress and increased expression of oxidative markers and adhesion molecules while antioxidants and inhibition of NF- $\mid$ B attenuate these changes [37,38]. Myeloperoxidase (MPO), an enzyme released from activated polymorphonuclear neutrophils has been linked to atrial fibrosis and remodeling [39]. MPO catalyzes the generation of reactive species like hypochlorous acid which affect intracellular signaling cascades in various cells and advance activation of pro-metaloproteinases and deposition of atrial collagen resulting in atrial arrhythmias. In an experimental setting MPO-deficient mice or rabbits were protected from AF $[40,41]$. In the same study, humans with AF had higher plasma concentrations of MPO and a larger MPO burden in right atrial tissue compared to control subjects. Furthermore, a recent study examining right atrial tissues from patients undergoing cardiac surgery indicated that monoamine oxidase represents an important source of ROS in human myocardium associated with POAF along with glutathione peroxidase [42]. However, it is currently unknown whether the mechanisms of mitochondrial dysfunction and eventual calcium overload would have a relevant pathogenic role in the development of POAF.

\section{Inflammation and POAF}

There is consistent evidence to support the influence of a surgeryrelated acute inflammation on the pathogenesis of POAF. This is largely based on association between levels and activity of white blood cells and incidence of POAF. Patients who have higher postoperative leukocytes count are significantly more likely to develop POAF [43-46] and patients developing POAF tend to have greater degree of monocyte activation as seen by higher expression of CD11b [47,48]. Moreover, the elevated pre and postoperative neutrophils/lymphocytes ratio in patients undergoing coronary bypass graft surgery can be associated with an increased incidence of POAF [49,50]. Exactly how these blood components can trigger POAF is not known. Previous work using animal models has shown that when activated neutrophils bind to cardiac myocytes they can cause changes in myocyte electrical activity that could be arrhythmogenic [51,52]. Cardiac surgery can induce a systemic inflammatory state (systemic inflammatory response syndrome, SIRS), whose cellular mechanisms of generation include the participation of ROS [45,53]. This systemic response is associated with the activation of cytoplasmic transcription factors such as NF- $\kappa \mathrm{B}$, which is key in the regulation of the inflammatory, immune, proliferative and apoptotic 
response [45,54]. In the case of NF- $\kappa \mathrm{B}$, the ROS, especially $\mathrm{H}_{2} \mathrm{O}_{2}$, would act at least at two levels: 1) oxidation of key kinases in the activation of I $\mathrm{KB}$ Kinase which activates the NF- $\kappa B[55,56]$ and, 2) Modulation of the transport of this factor from the cytoplasm to the nucleus $[45,57,58]$. Systemic inflammatory response syndrome has a mild modality, but on the occasion of prolonged surgeries or exaggerated elevation of serum cytokines, especially IL-6, it can progress to a severe systemic inflammatory state, with lethal consequences $[3,59]$ and it is likely that oxidative stress determines this difference. Markers of oxidative stress and inflammation are usually very ubiquitous in cardiac IR injury, therefore other markers that increase the specificity of the diagnosis in this type of arrythmias are clinically needed. The contribution of oxidative stress and inflammation are shown in Figure 1.

\section{mi-RNA and cardiovascular pathology}

MicroRNAs (miRNA) are a class of small non-coding RNA (20-25 nucleotides) that participate in gene regulation. In recent years, miRNAs have emerged as a key epigenetic mechanism in the development and functionality of the cardiovascular system. These molecular species regulate basic functions in virtually all cell types and therefore are directly associated with the pathophysiology of a large number of cardiovascular diseases $[60,61]$. Since its relatively recent discovery in extracellular fluids, miRNAs have been studied as potential biomarkers of several diseases. There are numerous studies that propose miRNAs as circulating biomarkers of different cardiovascular pathologies (myocardial infarction, coronary heart disease or heart failure, among others), even with physicochemical and biochemical properties superior to the conventional protein indicators currently used in clinical practice. They can be isolated from a variety of samples such as cell-conditioned media, plasma, serum, and other bodily fluids using a range of different methods such as sequential ultracentrifugation, density gradient separation, ultrafiltration, and commercial kits [62]. Currently, cardiovascular risk assessment is based exclusively on established classical risk factors such as hypertension, dyslipidemia, diabetes or smoking. Unfortunately, these traditional risk factors do not fully explain the risk of a cardiovascular event. Most of the events occur in patients with a low or intermediate risk that present a reduced number of classic cardiovascular risk factors. On the contrary, a large part of the individuals classified according to these factors as high risk

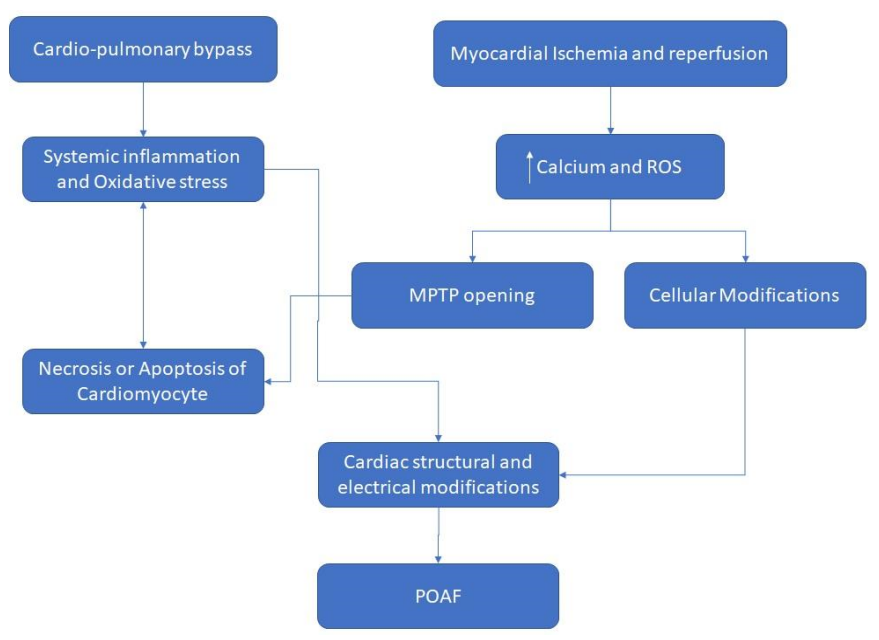

Figure 1. Proposed hypothesis for the role of oxidative stress and inflammation in the pathophysiology of postoperative atrial fibrillation in patients scheduled for cardiac surgery with cardiopulmonary bypass. ROS, reactive oxygen species; MPTP, mitochondrial permeability transition pore; $\mathrm{POAF}$, postoperative atrial fibrillation do not experience any cardiovascular episode; not even in the long term. Thus, there is a clear clinical interest in the development of new non-invasive and easily accessible biomarkers that significantly improve the predictive capacity of the algorithms developed to date, beyond the traditional risk factors [63].

\section{mi-RNA and atrial fibrillation}

The role of miRNA in cardiac arrhythmogenesis is in growing study in clinical and basic models [64]. miRNA targeting pathways associated with the regulation of cardiomyocyte metabolism (miR-208a and miR223) may alter the provision of energy substrate required to maintain AF [65], whereas other miRNAs are thought to play a central role in changes associated with structural (miR-133, miR-590, miR-29b, miR208, miR-638 and miR-150) and electrical remodeling of the cardiac tissue (miR-328, miR-1 and miR-26) [66]. Most of the studies to date examine miRNA expression in right or left atrial tissue, however, there is scarce evidence on the surrounding circulating miRNA in human AF [67-69]. Furthermore, current studies address the circulating miRNA signature in long-standing and paroxysmal AF and do not examine the role of miRNA in the new onset post-operative form of this arrhythmia. MiRNAs involved in cardiac electrical remodelling are miR-1, miR-26, miR-208a, miR-328 and miR-499. Their target genes are encoding ion channels, connexins or proteins involved in calcium signaling resulting in conduction slowing or shortening of the action potential duration, which are hallmarks of AF pathophysiology. In addition, mi-RNAs involved in cardiac structural remodelling are miR-21, miR- 26, miR29b, miR-30, miR-133 and miR-590. These miRNAs regulate genes encoding proteins that are involved in extracellular matrix turnover and pro- or anti-fibrotic signaling cascades leading to atrial fibrosis as the anatomical substrate for re-entry. Several options to agonize or antagonize miRNA effects were developed and successfully evaluated in vivo in AF-related animal models $[68,70,71]$. Overexpression of a miRNA that is downregulated in disease can be achieved by miRNA mimics. Mimics are synthetic double- stranded RNAs that are incorporated and processed by the cell-like endogenous miRNAs and therefore 'mimic' their effects [72]. However, mimics are not tissue-or cell-type specific and can therefore create undesirable off target effects. This can be avoided by using cardiotropic adenovirus-mediated miRNA transfer that has been shown for the treatment of heart failure in mice $[73,74]$ and cardiac hypertrophy in rats $[75,76]$. For antagonizing a pathological miRNA upregulation, several knockdown approaches are available including anti-miRNA oligonucleotides (antagomiRs) [77] or locked nucleic acid, [78] miRNA sponges, erasers or masks. AntagomiRs are synthetic oligonucleotides with miRNA complementary sequences that bind to endogenous miRNAs and thus, competitively inhibit them to bind to their target genes. MiRNA sponges [79] and erasers [77] are sequences of multiple miRNA sequences incorporated into a vector (e.g. a (cardiotropic) virus). While sponges contain only the seed sequence and might therefore inhibit various miRNAs, erasers are complementary to specific miRNAs. MiR masks, however, are single-stranded oligonucleotides that are complementary to a miRNA target sequence and can therefore specifically block single miRNAmRNA interactions $[80,81]$. All potential therapeutic interventions are currently based on an intramuscular or systemic application of these agents in vivo. In summary, progress in miRNA research has opened a window for establishing a new potential therapeutic intervention in the context of translational medicine. The future will show whether mi-RNAs can help to close the translational gap between underlying causes and specific treatment, which is currently thought to be one major problem in AF disease management. Also, the stability and the detection in biological fluids, such as PF, can increase the specificity of 
other markers such as the classical oxidative stress and inflammation, generating a new type of diagnostic cluster in POAF.

\section{Conclusion}

Despite the evidence of oxidative stress, inflammation and apoptosis occurrence in the atrial tissue and plasma of POAF patients post cardiac surgery with extracorporeal circulation, miRNA expression profiling results revealed a clear dissociation in expression levels between the atrial appendage and blood circulation. Whereas, an increase in some miRNA candidates such as higher levels of miR-1 and a decreased in miR- 133A that specifically negatively correlated with apoptosis was observed in the atrial tissue; however, the miR plasma equivalents were similar to their pre-CABG levels bringing into question the reliability of circulating miRs to serve as potential biomarkers for POAF in cardiac patients [82]. Nevertheless, an improved understanding of $\mathrm{miR}$ function would facilitate the design of novel strategies for cardio-protection against atrial tissue remodeling in POAF patients.

Finally, the use and validation of new markers such as miRNA in cardiac tissue and different fluids is important since their different expression profiles could bring us in a non-invasive way to what is induced by ischemia-reperfusion in myocardial tissue, its relationship with atrial remodeling and probable pharmacological targets that can be modelled.

\section{References}

1. Kramer PA, Chacko BK, George DJ, Zhi D, Wei CC, et al. (2015) Decreased Bioenergetic Health Index in monocytes isolated from the pericardial fluid and blood of post-operative cardiac surgery patients. Biosci Rep 35: e00237. [Crossref]

2. Hu YF, Chen YJ, Lin YJ, Chen SA (2015) Inflammation and the pathogenesis of atrial fibrillation. Nat Rev Cardiol 12: 230-243. [Crossref]

3. Zakkar M, Ascione R, James AF, Angelini GD, Suleiman MS, et al. (2015) Inflammation, oxidative stress and postoperative atrial fibrillation in cardiac surgery. Pharmacol Ther 154: 13-20. [Crossref]

4. Langlois PL, Hardy G, Manzanares W (2017) Omega-3 polyunsaturated fatty acids in cardiac surgery patients: An updated systematic review and meta-analysis. Clin Nutr 36: 737-746. [Crossref]

5. Chen S, Acou WJ, Kiuchi MG, Meyer C, Sommer P, et al. (2019) Association of Preoperative Renin-Angiotensin System Inhibitors With Prevention of Postoperative Atrial Fibrillation and Adverse Events: A Systematic Review and Meta-analysis. JAMA Netw Open 2: e194934. [Crossref]

6. Hogue CW Jr, Creswell LL, Gutterman DD, Fleisher LA (2005) Epidemiology, mechanisms, and risks: American College of Chest Physicians guidelines for the prevention and management of postoperative atrial fibrillation after cardiac surgery. Chest 128: 9-16. [Crossref]

7. Dobrev D, Aguilar M, Heijman J, Guichard JB, Nattel S, et al. (2019) Postoperative atrial fibrillation: mechanisms, manifestations and management. Nat Rev Cardiol 16: 417-436. [Crossref]

8. Andrade, J, Khairy, P, Dobrev D, Nattel S (2014) The clinical profile and pathophysiology of atrial fibrillation: relationships among clinical features, epidemiology, and mechanisms. Circ Res 114: 1453-1468. [Crossref]

9. Higa S, Lo LW, Chen SA (2018) Catheter Ablation of Paroxysmal Atrial Fibrillation Originating from Non-pulmonary Vein Areas. Arrhythm Electrophysiol Rev 7: 273-281. [Crossref]

10. Rodrigo R, Cereceda M, Castillo R, Asenjo R, Zamorano J, et al. (2008) Prevention of atrial fibrillation following cardiac surgery: basis for a novel therapeutic strategy based on non-hypoxic myocardial preconditioning. Pharmacol Ther 118: 104-127. [Crossref]

11. Pokushalov E, Kozlov B, Romanov A, Strelnikov A, Bayramova S, et al. (2015) Longterm suppression of atrial fibrillation by botulinum toxin injection into epicardial fat pads in patients undergoing cardiac surgery: one-year follow-up of a randomized pilot study. Circ Arrhythm Electrophysiol 8: 1334-1341. [Crossref]
12. Korantzopoulos P, Letsas K, Fragakis N, Tse G, Liu T, et al. (2018) Oxidative stress and atrial fibrillation: an update. Free Radic Res 52: 1199-1209. [Crossref]

13. Becker LB (2004) New concepts in reactive oxygen species and cardiovascular reperfusion physiology. Cardiovasc Res 61: 461-470. [Crossref]

14. Farías JG, Herrera EA, Carrasco-Pozo C, Sotomayor-Zárate R, Cruz G, et al. (2016) Pharmacological models and approaches for pathophysiological conditions associated with hypoxia and oxidative stress. Pharmacol Ther 158: 1-23. [Crossref]

15. Gutierrez, A, Van Wagoner DR (2015) Oxidant and Inflammatory Mechanisms and Targeted Therapy in Atrial Fibrillation: An Update. J Cardiovasc Pharmacol 66: 523 529. [Crossref]

16. Harada M, Van Wagoner DR, Nattel S (2015) Role of inflammation in atrial fibrillation pathophysiology and management. Circ J 79: 495-502. [Crossref]

17. Vieira MJ, Teixeira R, Gonçalves L, Gersh BJ (2014) Left atrial mechanics: echocardiographic assessment and clinical implications. J Am Soc Echocardiogr 27: 463-478. [Crossref]

18. Petersen F, Rodrigo R, Richter M, Kostin S (2017) The effects of polyunsaturated fatty acids and antioxidant vitamins on atrial oxidative stress, nitrotyrosine residues, and connexins following extracorporeal circulation in patients undergoing cardiac surgery. Mol Cell Biochem 433: 27-40. [Crossref]

19. Zhang G, Abuduoufu A, Zhou X, Li Y, Zhang L, et al. (2019) Monocyte Chemoattractant Protein-1-Induced Protein in Age-Related Atrial Fibrillation and Its Association with Circulating Fibrosis Biomarkers. Cardiology 142: 244-249. [Crossref]

20. Wu MY, Yiang GT, Liao WT, Tsai AP, Cheng YL, et al. (2018) Current Mechanistic Concepts in Ischemia and Reperfusion Injury. Cell Physiol Biochem 46: 1650-1667. [Crossref]

21. Muzáková V, Kandár R, Vojtísek P, Skalický J, Cervinková Z, et al. (2000) Selective antioxidant enzymes during ischemia/reperfusion in myocardial infarction. Physiol Res 49: 315-322 [Crossref]

22. Bai J, Lyden PD (2015) Revisiting cerebral postischemic reperfusion injury: new insights in understanding reperfusion failure, hemorrhage, and edema. Int J Stroke 10: 143-152. [Crossref]

23. Himmetoglu S, Dincer Y, Bozcali E, Ali Vural V, Akcay T, et al. (2009) Oxidative DNA damage and antioxidant defense after reperfusion in acute myocardial infarction. J Investig Med 57: 595-599. [Crossref]

24. González-Montero J, Brito R, Gajardo AI, Rodrigo R (2018) Myocardial reperfusion injury and oxidative stress: Therapeutic opportunities. World J Cardiol 10: 74-86. [Crossref]

25. Ramlawi B, Otu H, Mieno S, Boodhwani M, Sodha NR, et al. (2007) Oxidative stress and atrial fibrillation after cardiac surgery: a case-control study. Ann Thorac Surg 84 1166-1172. [Crossref]

26. Schipper DA, Marsh KM, Ferng AS, Duncker DJ, Laman JD, et al. (2016) The Critical Role of Bioenergetics in Donor Cardiac Allograft Preservation. $J$ Cardiovasc Transl Res 9: 176-183. [Crossref]

27. Nakamura K, Miura D, Kusano KF, Fujimoto Y, Sumita-Yoshikawa W, et al. (2009) 4-Hydroxy-2-nonenal induces calcium overload via the generation of reactive oxygen species in isolated rat cardiac myocytes. J Card Fail 15: 709-716. [Crossref]

28. Xiao W (2004) Advances in NF-kappaB signaling transduction and transcription. Cell Mol Immunol 1: 425-435. [Crossref]

29. Yang JH, Kim KM, Kim MG, Seo KH, Han JY, et al. (2015) Role of sestrin2 in the regulation of proinflammatory signaling in macrophages. Free Radic Biol Med 78: 156167. [Crossref]

30. Valko M, Leibfritz D, Moncol J, Cronin MT, Mazur M, et al. (2007) Free radicals and antioxidants in normal physiological functions and human disease. Int J Biochem Cell Biol 39: 44-84. [Crossref]

31. Mora-Ruíz MD, Blanco-Favela F, Chávez Rueda AK, Legorreta-Haguet MV, ChávezSánchez L, et al. (2019) Role of interleukin-17 in acute myocardial infarction. Mol Immunol 107: 71-78. [Crossref]

32. Jahangiri A, Leifert WR, Kind KL, McMurchie EJ (2006) Dietary fish oil alters cardiomyocyte Ca2+ dynamics and antioxidant status. Free Radic Biol Med 40: 1592 1602. [Crossref]

33. Zhou T, Prather ER, Garrison DE, Zuo L (2018) Interplay between ROS and Antioxidants during Ischemia-Reperfusion Injuries in Cardiac and Skeletal Muscle. Int J Mol Sci 19: E417. [Crossref] 
34. Li X, Yang X, Li Y, Yuan M, Tian C, et al. (2018) Mitochondria and the Pathophysiological Mechanism of Atrial Fibrillation. Curr Pharm Des 24: 3055-3061. [Crossref]

35. Xie W, Santulli G, Reiken SR, Yuan Q, Osborne BW, et al. (2015) Mitochondrial oxidative stress promotes atrial fibrillation. Sci Rep 5: 11427. [Crossref]

36. Zuo S, Li LL, Ruan YF, Jiang L, Li X, et al. (2018) Acute administration of tumour necrosis factor- $\alpha$ induces spontaneous calcium release via the reactive oxygen species pathway in atrial myocytes. Europace 20: 1367-1374. [Crossref]

37. Bukowska A, Schild L, Keilhoff G, Hirte D (2006) Mitochondrial dysfunction and redox signaling in atrial tachyarrhythmia. Exp Biol Med 233: 558-574. [Crossref]

38. Aschar-Sobbi R, Izaddoustdar F, Korogyi AS, Wang Q, Farman GP, et al. (2015) Increased atrial arrhythmia susceptibility induced by intense endurance exercise in mice requires TNF $\alpha$. Nat Commun 6: 6018. [Crossref]

39. Friedrichs K, Baldus S, Klinke A (2012) Fibrosis in Atrial Fibrillation - Role of Reactive Species and MPO. Front Physiol 3: 214. [Crossref]

40. Rudolph V, Andrié RP, Rudolph TK, Friedrichs K, Klinke A, et al. (2010) Myeloperoxidase acts as a profibrotic mediator of atrial fibrillation. Nat Med 16: 470474. [Crossref]

41. Yang Q, Qi X, Dang Y, Li Y, Song X, et al. (2016) Effects of atorvastatin on atrial remodeling in a rabbit model of atrial fibrillation produced by rapid atrial pacing. BMC Cardiovasc Disord 16: 142.[Crossref]

42. Anderson EJ, Efird JT, Davies SW, O’Neal WT, Thayne KA, et al. (2014) Monoamine oxidase is a major determinant of redox balance in human atrial myocardium and is associated with postoperative atrial fibrillation. J Am Heart Assoc 3: e000713. [Crossref]

43. Lamm G, Auer J, Weber T, Berent R, Ng C, et al. (2006) Postoperative white blood cell count predicts atrial fibrillation after cardiac surgery. J Cardiothorac Vasc Anesth 20: 51-56. [Crossref]

44. Fontes ML, Amar D, Kulak A, Koval K, Zhang H, et al. (2009) Increased preoperative white blood cell count predicts postoperative atrial fibrillation after coronary artery bypass surgery. J Cardiothorac Vasc Anesth 23: 484-487. [Crossref]

45. Castillo R, Rodrigo R, Perez F, Cereceda M, Asenjo R, et al. (2011) Antioxidant therapy reduces oxidative and inflammatory tissue damage in patients subjected to cardiac surgery with extracorporeal circulation. Basic Clin Pharmacol Toxicol 108: 256-262. [Crossref]

46. Sabol F, Jakubova M, Mitro P, Bomba A, Chmelárová A, et al. (2012) Is there a relationship between inflammatory markers, oxidative stress and postoperative atrial fibrillation?. Vnitr Lek 58: 730-734. [Crossref]

47. Fontes ML, Mathew JP, Rinder HM, Zelterman D, Smith BR, et al. (2005) Multicenter Study of Perioperative Ischemia (McSPI) Research Group. Atrial fibrillation after cardiac surgery/cardiopulmonary bypass is associated with monocyte activation. Anesth Analg 101: 17-23. [Crossref]

48. Friedrichs K, Adam M, Remane L, Mollenhauer M, Rudolph V, et al. (2014) Induction of atrial fibrillation by neutrophils critically depends on CD11b/CD18 integrins. PLoS One 9: e89307. [Crossref]

49. Gibson PH, Cuthbertson BH, Croal BL, Rae D, EI-Shafei H, et al. (2010) Usefulness of neutrophil/lymphocyte ratio as predictor of new-onset atrial fibrillation after coronary artery bypass grafting. Am J Cardiol 105: 186-191. [Crossref]

50. Rodrigo R, Korantzopoulos P, Cereceda M, Asenjo R, Zamorano J, et al. (2013) A randomized controlled trial to prevent post-operative atrial fibrillation by antioxidant reinforcement. J Am Coll Cardiol 62: 1457-1465. [Crossref]

51. Hoffman BF, Feinmark SD, Guo SD (1997) Electrophysiologic effects of interactions between activated canine neutrophils and cardiac myocytes. J Cardiovasc Electrophysio 8: 679-687. [Crossref]

52. Ward CA, Bazzazi H, Clark RB, Nygren A, Giles WR, et al. (2006) Actions of emigrated neutrophils on $\mathrm{Na}(+)$ and $\mathrm{K}(+)$ currents in rat ventricular myocytes. Prog Biophys Mol Biol 90: 249-269. [Crossref]

53. Bangert A, Andrassy M, Müller AM, Bockstahler M, Fischer A, et al. (2016) Critica role of RAGE and HMGB1 in inflammatory heart disease. Proc Natl Acad Sci U S A 113: E155-164. [Crossref]

54. Yeh YC, Yu LC, Wu CY, Cheng YJ, Lee CT, et al. (2017) Effects of endotoxin absorber hemoperfusion on microcirculation in septic pigs. J Surg Res 211: 242-250. [Crossref]

55. Mabb AM, Wuerzberger-Davis SM, Miyamoto S (2006) PIASy mediates NEMO sumoylation and NF-kappaB activation in response to genotoxic stress. Nat Cell Biol 8: 986-993. [Crossref]
56. Tsai KH, Wang WJ, Lin CW, Pai P, Lai TY, et al. (2012) NADPH oxidase-derived superoxide anion-induced apoptosis is mediated via the JNK-dependent activation of NF-kB in cardiomyocytes exposed to high glucose. J Cell Physiol 227: 1347-1357. [Crossref]

57. De Oliveira-Marques V, Cyrne L, Marinho HS, Antunes F (2007) A quantitative study of NF-kappaB activation by $\mathrm{H} 2 \mathrm{O} 2$ : relevance in inflammation and synergy with TNFalpha. J Immunol 178: 3893-3902. [Crossref]

58. Cyrne L, Oliveira-Marques V, Marinho HS, Antunes F (2013) $\mathrm{H} 2 \mathrm{O} 2$ in the induction of NF-кB-dependent selective gene expression. Methods Enzymol 528: 173-188. [Crossref]

59. Magovern JA, Singh D, Teekell-Taylor L, Scalise D, McGregor W, et al. (2007) Preoperative clinical factors are important determinants of the inflammatory state before and after heart surgery. ASAIO J 53: 316-319. [Crossref]

60. De Gonzalo-Calvo D, Iglesias-Gutiérrez E, Llorente-Cortés V (2017) Epigenetic Biomarkers and Cardiovascular Disease: Circulating MicroRNAs. Rev Esp Cardiol 70 763-769. [Crossref]

61. Pogribny IP (2018) MicroRNAs as biomarkers for clinical studies. Exp Biol Med 243 283-290. [Crossref]

62. Sharma S, Scholz-Romero K, Rice GE, Salomon C (2018) Methods to Enrich Exosomes from Conditioned Media and Biological Fluids. Methods Mol Biol 1710 103-115. [Crossref]

63. Mayr M, Zampetaki A, Kiechl S (2013) MicroRNA biomarkers for failing hearts?. Eur Heart J 34: 2782-2783. [Crossref]

64. Navickas R, Gal D, Laucevičius A, Taparauskaité A, Zdanyté M, et al. (2016) Identifying circulating microRNAs as biomarkers of cardiovascular disease: a systematic review. Cardiovasc Res 111: 322-337.[Crossref]

65. Pinti MV, Hathaway QA, Hollander JM (2017) Role of microRNA in metabolic shift during heart failure. Am J Physiol Heart Circ Physiol 312: 33-45. [Crossref]

66. Sharma D, Li G, Xu G, Liu Y, Xu Y, et al. (2011) Atrial remodeling in atrial fibrillation and some related microRNAs. Cardiology 120: 111-121. [Crossref]

67. Liu Z, Zhou C, Liu Y, Wang S, Ye P, et al. (2012) The expression levels of plasma micoRNAs in atrial fibrillation patients. PLoS One 7: e44906. [Crossref]

68. Dawson K, Wakili R, Ordög B, Clauss S, Chen Y, et al. (2013) MicroRNA29: a mechanistic contributor and potential biomarker in atrial fibrillation. Circulation 127: 1466-1475. [Crossref]

69. Zhou Q, Maleck C, Von Ungern-Sternberg S, Neupane B, Heinzmann D, et al (2018) Circulating MicroRNA-21 Correlates With Left Atrial Low-Voltage Areas and Is Associated With Procedure Outcome in Patients Undergoing Atrial Fibrillation Ablation. Circ Arrhythm Electrophysiol 11: e006242. [Crossref]

70. Cardin S, Guasch E, Luo X, Naud P, Le QK, et al. (2012) Role for MicroRNA-21 in atrial profibrillatory fibrotic remodeling associated with experimental postinfarction heart failure. Circ Arrhythm Electrophysiol 5: 1027-1035. [Crossref]

71. Yuan CT, Li XX, Cheng QJ, Wang YH, Wang JH, et al. (2015) MiR-30a regulates the atrial fibrillation-induced myocardial fibrosis by targeting snail 1. Int J Clin Exp Patho 8: 15527-15536. [Crossref]

72. Wang Z (2011) The guideline of the design and validation of MiRNA mimics. Methods Mol Biol 676: 211-223. [Crossref]

73. Wahlquist C, Jeong D, Rojas-Munoz A, Kho C, Lee A, et al. (2014) Inhibition of miR25 improves cardiac contractility in the failing heart. Nature 508: 531-535. [Crossref]

74. Lim TB, Aliwarga E, Luu TDA, Li YP, Ng SL, et al. (2019) Targeting the highly abundant circular RNA circSlc8a1 in cardiomyocytes attenuates pressure overload induced hypertrophy. Cardiovasc Res pii: cvz130. [Crossref]

75. Karakikes I, Chaanine AH, Kang S, Mukete BN, Jeong D, et al. (2013) Therapeutic cardiac-targeted delivery of miR-1 reverses pressure overload-induced cardiac hypertrophy and attenuates pathological remodeling. J Am Heart Assoc 2: e000078. [Crossref]

76. Jahn C, Bär C, Thum T (2019) CircSlc8a1, breaking a vicious circle in cardiac hypertrophy. Cardiovasc Res pii: cvz147. [Crossref]

77. Caroli A, Cardillo MT, Galea R, Biasucci LM (2013) Potential therapeutic role of microRNAs in ischemic heart disease. J Cardiol 61: 315-320. [Crossref] 
78. Kauppinen S, Vester B, Wengel J (2005) Locked nucleic acid (LNA): High affinity targeting of RNA for diagnostics and therapeutics. Drug Discov Today Technol 2: 287-290. [Crossref]

79. Ebert MS, Sharp PA (2010) MicroRNA sponges: progress and possibilities. RNA 16: 2043-2050. [Crossref]

80. Wang Z (2011) The principles of MiRNA-masking antisense oligonucleotides technology. Methods Mol Biol 676: 43-49. [Crossref]
81. Franceschini A, Meier R, Casanova A, Kreibich S, Daga N, et al. (2014) Specific inhibition of diverse pathogens in human cells by synthetic microRNA-like oligonucleotides inferred from RNAi screens. Proc Natl Acad Sci 111: 4548-4553.

82. Tsoporis JN, Fazio A, Rizos IK, Izhar S, Proteau G, et al. (2018) Increased right atrial appendage apoptosis is associated with differential regulation of candidate MicroRNAs 1 and 133A in patients who developed atrial fibrillation after cardiac surgery. $J$ Mol Cell Cardiol 121: 25-32. [Crossref]

Copyright: C2019 Castillo RL. This is an open-access article distributed under the terms of the Creative Commons Attribution License, which permits unrestricted use, distribution, and reproduction in any medium, provided the original author and source are credited. 